\title{
HBV, HCV and HIV Seroprevalence in Syrian Refugee Patient Population Undergoing Preoperative Anaesthetic Assessment: A 10-Year Survey in a Tertiary Teaching Hospital
}

\author{
Mehmet Çömez ${ }^{1}$, Tayibe Bal $^{2}$, and Mehmet Çabalak ${ }^{3}$ \\ ${ }^{1}$ Hatay Mustafa Kemal University \\ ${ }^{2}$ Mustafa Kemal Universitesi Tayfur Ata Sokmen Tip Fakultesi \\ ${ }^{3}$ Affiliation not available
}

June 9, 2021

\begin{abstract}
Objective: Migration can lead to a change in the demographic dynamics of host populations in terms of communicable diseases in destination countries. This is a potential public health challenge for health authorities. HBV and HCV infections can lead to the development of chronic liver diseases, cirrhosis and hepatocellular carcinoma, and HIV infection can lead to the development of serious opportunistic diseases. The aim of this study is to evaluate the seroprevalence of HBV, HCV and HIV in Syrian refugees and Turkish patients who were evaluated preoperatively in our hospital. Materials and methods: HBsAg, Anti-HBs, Anti-HBc, Anti-HCV and Anti-HIV results of Syrian refugee and Turkish patients who applied to surgical clinics between 2011-2021 were retrospectively reviewed. Results: The study is comprised of 54446 patients: Turkish patient group (n=20569) and Syrian refugee patient group $(\mathrm{n}=33877)$. The Syrian refugee patients had a significantly higher HBsAg seropositivity rate and a significantly lower anti-HBs seropositivity rate than the Turkish patients $(\mathrm{p}=0.002$ and $\mathrm{p}<0.001$, respectively). The antiHCV and anti-HIV seropositivity rates were similar. The annual preoperative prevalance of HBsAg seropositivity in the Syrian refugee patients tended to significantly decrease gradually from year 2011 to year 2021 ( $p<0.001$ for [?]30 and $p=0.001$ for $>30$ years old). Conclusion: As a result, although HBV seroprevalence gradually decreases and HCV and HIV seroprevalence is low; screening, information and treatment programs should be given due importance because of the serious disease potential and preventable conditions with precautions. In addition, preoperative screening of refugee patients coming for major surgery may be important for the safety of healthcare professionals.
\end{abstract}

\section{Introduction}

Migration is recognized as an independent social determinant of health. Large-scale migration can contribute to a change in the demographic dynamics of host populations in terms of communicable diseases in destination countries. Current mass movement from high or medium prevalence regions is a potential public health challenge for health authorities in countries with low prevalence of infectious diseases [1].

The Syrian civil war, which has been ongoing since 2011, led to the biggest refugee crisis since World War II. 3.658 million refugees were reported in Turkey in September 2019 [2, 3]. Refugees bring many infectious diseases that endanger the health of both themselves and the host population [4]. Infections caused by hepatitis $\mathrm{B}$ virus (HBV) and hepatitis $\mathrm{C}$ virüs (HCV) lead to the development of chronic liver diseases, cirrhosis and hepatocellular carcinoma, while human immunodeficiency virus (HIV) infection can lead to the development of serious opportunistic infections. According to the World Health Organization (WHO), an estimated number of 500 million people live with chronic viral hepatitis, making HBV and HCV one of the most virulent infectious diseases worldwide $[5,6]$. At least 1.3 million deaths per year can be attributed to 
chronic liver disease caused by HBV and $\mathrm{HCV}[6,7]$. Also, viral hepatitis is largely responsible for the global increase in liver cancer.

More than $90 \%$ of the Syrian refugee population live in the community and mostly in big provinces such as Istanbul, Gaziantep, Hatay and Sanliurfa. Hatay province hosts 435,953 Syrian refugees [8]. Our city, which is close to the war zone, is at a higher risk of infectious diseases compared to other regions, as there are many applications for emergency and elective operations to our institution, which is a third level training and research hospital. In order to minimize the risk of occupational contamination, every patient may be potentially infected and there is a need to take protective measures accordingly. In addition, it is important to know the current prevalence of these diseases in establishing appropriate health policies for refugees. The aim of this study is to evaluate the HBV, HCV and HIV seroprevalence of Syrian refugee patients who were evaluated preoperatively in our hospital and to compare them with the results of Turkish patients.

\section{Materials and methods}

This study was approved by the Non-Interventional Clinical Research Ethics Committee of XXXXXXXXXXXXX (approval number: 22/04 / 2021-05). hepatitis B surfage antigen (HBsAg), hepatitis B surfage antibody (Anti-HBs), hepatitis B core antibody (Anti-HBc), hepatitis C virüs antibody (Anti-HCV) and human immunodeficiency virüs antibody (Anti-HIV) results of Syrian refugees and Turkish patients of all age groups who applied to XXXXXXXXXXXX Hospital between 2011-2021 to be operated in surgical clinics were retrospectively screened and a comparison was made between the two groups. Serum samples were tested for HBsAg, anti-HCV, anti- HIV, total anti-HBc, and anti-hepatitis B surface antibody (HBs) using commercial immunoenzymatic assays (Abbott Architect i2000SR, Illinois, USA). Anti-HIV reactivity was always confirmed by a western blot assay, which identifies both HIV-1 and HIV-2 strains. The demographic data of the patients were analyzed retrospectively from the hospital electronic information system and patient files. Duplicate records were removed.

Patient characteristics were determined as age, gender, race and year of admission to the hospital. Patients with positive HBs Ag but with normal ALT and AST levels and negative HBV DNA were accepted as HBV carriers. Patients with Hbs Ag and Anti-HBc IgG negative but positive for Anti-HBs were considered vaccinated. Detection of anti-HBc IgG positivity alone was accepted as isolated Anti-HBc IgG positivity. Patients who were found to be negative for all three parameters (HBs Ag, Anti HBs and Anti HBc) were considered to have never encountered hepatitis B. All analyses were carried out using SPSS, version 23 software (SPSS Inc, Chicago IL, USA). The Shapiro Wilk normality test was used to examine normality of distribution. Categorical variables were presented as frequencies (percentages) and compared with Chi-square test (or Fisher's exact test, where appropriate). Non-normally distributed continuous variables were presented as median with interquartile range (IQR, 25th and 75th percentiles) and compared with the Mann-Whitney $\mathrm{U}$ test between the groups.

\section{Results}

The study is comprised of 54446 patients, divided into two groups: Turkish patient group $(\mathrm{n}=20569)$ and Syrian refugee patient group $(\mathrm{n}=33877)$. The median age of the patients was $41(28-59)$ years and $44.8 \%$ $(\mathrm{n}=24396)$ were male. The epidemiological characteristics and preoperative seroprevalance of HBV, HCV, HIV serological markers in the Syrian refugee and Turkish patients are shown in Table 1.

Although the Syrian refugee patients were significantly younger than the Turkish patients, Syrian refugee patients had a significantly higher HBsAg seropositivity rate and a significantly lower anti-HBs seropositivity rate than the Turkish patients $(\mathrm{p}<0.001, \mathrm{p}=0.002$ and $\mathrm{p}<0.001$, respectively). The anti-HBc, anti-HCV and anti-HIV seropositivity rates were similar between the two groups $(\mathrm{p}=0.258, \mathrm{p}=0.457$ and $\mathrm{p}=1.000$, respectively) (Table 1).

The comparisons of seropositivity of HBV markers between two groups according to age are shown in Table 2. Syrian refugee patients 15-year-old or younger and in the 16-30 age group had a significantly higher rate of HBsAg seropositivity than the Turkish patients in the same age groups ( $\mathrm{p}=0.007$ and $\mathrm{p}=0.002$, respectively). 
However, the rates of HBsAg seropositivity between two groups were similar in other age groups (Table 2).

The annual preoperative prevalance of HBsAg seropositivity in the Syrian patients (both in 30-year-old or younger and in over 30-year-old patients) tended to significantly decrease gradually from year 2011 to year 2021 ( $p<0.001$ and $p=0.001$, respectively). However, no significant changes were seen in the prevalance of HBsAg seropositivity in the Turkish patients in the same age groups $(\mathrm{p}=0.910$ and $\mathrm{p}=0.483$, respectively) (Figure 1). Although anti HCV seropositivity was similar between Syrian refugee and Turkish patients in $<15,16-30,46-60$ and $>60$ age groups, it was significantly higher in Syrian refugee patients in the 31-45 age group (p:0.037) (Table 3).

\section{Discussion}

Millions of people around the world emigrate from their homeland due to economic, political and war reasons. Our border city, Hatay, received significant immigration due to the Syrian civil war that started in 2011, and many people who were injured in the war applied to our hospital due to the need for urgent surgical operation. It is important to determine the infectious disease prevalence of our city due to migration and patient transfers. According to our latest information, this is the first preoperative hepatitis serology study conducted in Syrian refugee patients.

According to the HBV carrier rate, the world is divided into 3 regions with high, medium and low endemics. The Center for Disease Control and Prevention in Atlanta, USA recommends screening for HBV infection in people from countries with an HBsAg prevalence greater than $2 \%$. Turkey is a moderately endemic country for HBV with a prevalence of 4\% (2-8\%) [9]. Vaccination against HBV in Turkey started in 1998 and vaccination rates reached $98 \%$ in 2016 [10]. Vaccination against HBV in Syria started in 1991 and the pre-war vaccination rate reached $83 \%$ in 2008 [11, 12]. Also, Syria is one of the middle endemic countries for HBV [13].

In this study, the Syrian refugee patient population was 33877 and the Turkish patient population was 20569. The average age was significantly lower in Syrian patients compared to Turkish patients. However, there was no gender difference between the groups $(\mathrm{p}<0.001$ and $\mathrm{p}=0.360$, respectively). There was a significantly higher HBsAg seropositivity rates in Syrian refugee patients (2.3\%) compared to Turkish patients (1.9\%) $(\mathrm{p}=0.002)$. In a study conducted in Karabük, Aşkın et al. [14] reported HBsAg seropositivity as 2.3\% in the general patient population of Syrian refugees. In a study conducted in Kahramanmaraş, Ozkaya et al. [15] reported HBsAg seropositivity as $3.6 \%$ in the general patient population of Syrian refugees. In a study conducted in Ankara, Tümtürk et al. [16] reported that HBsAg seropositivity was 5.7\% in the general patient population of Syrian refugees. When evaluated according to age groups, HBsAg seropositivity was significantly higher in Syrian refugee patients under the age of 15 and in the 15-30 age group. There was no difference in other age groups. This may be due to the fact that refugee children who came to Turkey missed a large number of vaccination periods due to the collapse of the vaccination system in their country of origin $[17,18]$.

The annual preoperative prevalence of HBsAg seropositivity in Syrian refugee patients (both [?]30 and >30 years old) tended to gradually decline significantly from 2011 to 2021 ( $p<0.001$ and $p=0.001$, respectively). However, there was no significant change in the prevalence of HBsAg seropositivity in Turkish patients in the same age group $(\mathrm{p}=0.910$ and $\mathrm{p}=0.483$, respectively). This may be due to the collapse of the vaccination system in the country of origin during the first period of war and migration and more crowded living environments such as camps. In the later period, it can be attributed to the inclusion of all Syrian refugee children in the national vaccination program and the improvement of socioeconomic conditions (such as free access to health and treatment, children's education, work permits and free access to vocational training) $[17,19,20]$.

Anti HBs seropositivity was significantly lower in Syrian refugee patients (40.8\%) compared to Turkish patients $(42.5 \%)(\mathrm{p}<0.001)$. No difference was found between Syrian refugee and Turkish patients in terms of anti-HBs seropositivity under the age of $15(\mathrm{p}<0.001)$. This may be due to the fact that all Syrian refugee children who arrived in Turkey are included in the national vaccination program [19]. According to the data of the Turkish Ministry of Health, the number of Syrian refugee children vaccinated was reported as 59743 
in 2014, 100244 in 2015, 148172 in 2016 and 269085 in 2017 [19]. Anti HBs seropositivity was lower in Syrian refugee patients compared to Turkish patients in the 16-30 age $(\mathrm{p}<0.01)$ and 31-45 age (p: 0.013) groups. This was attributed to the poor socioeconomic conditions in the war zone and the absence of vaccination tracking $[17,18]$. No significant difference was found between Syrian refugee and Turkish patients over the age of 46. In accordance with this study, Ozkaya et al. [15] found a significant difference in anti-HBs seropositivity between Syrian refugees (34.9\%) and Turkish patients (43.4\%).

According to WHO data, Syria is among endemic areas with a low anti-HCV seropositivity rate [21]. Consistent with this, anti HCV seropositivity was 1.2\% in Syrian refugee patients and $1.1 \%$ in Turkish patients in this study. There was no significant difference between Syrian refugee and Turkish patients in terms of anti-HCV seropositivity. Anti-HCV seropositivity was significantly higher in Syrian refugee patients aged 31-45 (p:0.037). However, it was similar to Turkish patients in other age groups. Consistent with this study, Ozkaya et al. [15] reported 1.8\% anti-HCV seropositivity. In another study, Aşgin et al. [14] reported it as 1\%. Tümtürk et al. [16] found $2.46 \%$ in a study they conducted on a small population (244 Syrian refugees). In a meta-analysis, Chemaitelly et al. [22] reported the anti-HCV seropositivity rate as $48.8-75 \%$ in hemodialysis patients, $21 \%$ in drug users and $20.5 \%$ in hemophilia patients in the Syrian population. These high rates may be due to the presence of serious risk factors in patients.

Syria has very low HIV prevalence [23]. In this study, 1 HIV $(+)$ patient was identified in 33877 Syrian refugee patients and only 1 in 20569 Turkish patients. Inci et al. [24] did not find any anti HIV (+) patients among 300 Syrian refugees in their study. In another study conducted by Tümtürk et al. [16], they did not find any anti HIV $(+)$ patients among 244 Syrian refugees.

We have some limitations in this study. This study was conducted on Syrian refugee patients, who had a high population, but had preoperative anesthetic evaluation in a single center. Therefore, multi-center studies are needed as our results may not reflect the serological data of all Syrian refugees. Since this study was retrospective, the medical history and risk factors of the patients could not be obtained.

In this study, information on HBV, HCV and HIV seroprevalence of high population of Syrian refugees who came for emergency and elective surgical operations from the ongoing Syrian civil war since 2011 was presented. In the Syrian refugee population, HBsAg seroprevalence was high and anti HBsAg seroprevalence was low. However, due to the vaccination studies conducted in Turkey, especially in the pediatric age group in Syrian refugees, HBsAg seroprevalence has gradually decreased and anti-HBs seroprevalence has increased gradually in the 10-year period. HCV and HIV rates are very low in both Turkish and Syrian populations.

As a result, although HBV seroprevalence decreases gradually and HCV and HIV seroprevalence is low, due attention should be paid to screening, information and treatment programs due to the serious disease potential and preventable conditions. In addition, healthcare professionals' strict adherence to standard protection measures, training, vaccination against HBV and preoperative screening of refugee patients coming for major surgery may be important for the safety of healthcare professionals.

\section{References}

1. Thijssen M, Lemey P, Amini-Bavil-Olyaee S, Dellicour S, Alavian SM, Tacke F, et al. Mass migration to Europe: an opportunity for elimination of hepatitis B virus? The Lancet Gastroenterology \& Hepatology. 2019;4(4):315-23.

2. Nimer NA. A review on emerging and reemerging of infectious diseases in Jordan: the aftermath of the Syrian crises. Canadian Journal of Infectious Diseases and Medical Microbiology. 2018;2018.

3. Assi R, Özger-İlhan S, İlhan M. Health needs and access to health care: The case of Syrian refugees in Turkey. Public Health. 2019;172:146-52.

4. Pottie K, Mayhew AD, Morton RL, Greenaway C, Akl EA, Rahman P, et al. Prevention and assessment of infectious diseases among children and adult migrants arriving to the European Union/European Economic 
Association: A protocol for a suite of systematic reviews for public health and health systems. BMJ open. 2017;7(9):e014608.

5. García-Tardón N, Gresnigt TM, Fofanah AB, Grobusch MP. Hepatitis B and C in tonkolili province, sierra leone. The Lancet. 2017;390(10101):1485.

6. Organization WH. Global hepatitis report 2017: World Health Organization; 2017.

7. Lavanchy D. Hepatitis B virus epidemiology, disease burden, treatment, and current and emerging prevention and control measures. Journal of viral hepatitis. 2004;11(2):97-107.

8. Directorate general of migration management of Turkish Ministry of interior temporary protection statistics. 2021 [cited 2021]. Available from: https://en.goc.gov.tr/temporary-protection27.

9. Tozun N, Ozdogan O, Cakaloglu Y, Idilman R, Karasu Z, Akarca U, et al. Seroprevalence of hepatitis B and $\mathrm{C}$ virus infections and risk factors in Turkey: a fieldwork TURHEP study. Clinical Microbiology and Infection. 2015;21(11):1020-6.

10. Turkey viral hepatitis prevention and control program. 2018-2023 2018 [2021]. Available from: https://www.globalhep.org.

11. Köse Ş, Ödemiş I, Çelik D, Tatar G, Akbulut I, Çiftdoğan DY. Hepatitis A, B, C and HIV seroprevalence among Syrian refugee children admitted to outpatient clinics. Le infezioni in medicina. 2017;25(4):339-43.

12. Bashour H, Muhjazi G. Hepatitis B and C in the Syrian Arab Republic: a review. EMHJ-Eastern Mediterranean Health Journal. 2016;22(4):267-73.

13. Antaki N, Haffar S, Deeb SA, Assaad F, Abou Harb R, Zeibane N, et al. High prevalence of HBV genotype D in Syria and the clinical characteristics of hepatitis B e antigen-negative chronic hepatitis B. Epidemiology \& Infection. 2010;138(1):40-4.

14. AŞGIN N, SATILMIŞ Ş. An Evaluation of Hepatitis B Virus and Hepatitis C Virus Frequency and the Anti-hepatitis B Surface Seropositivity of Syrian Refugees in the Karabük Province. Viral Hepatitis Journal. 2019;25(3):84-7.

15. ÖZKAYA E, KİRIŞCI Ö, ÇALIŞKAN A, TÜMER S, ŞENOL H. Son İki Yılda Kahramanmaraş Necip Fazıl Şehir Hastanesine Başvuran Suriye Kökenli ve Suriye Kökenli Olmayan Hastalara Ait Serum Örneklerindeki HBsAg, Anti-HBs ve Anti-HCV Pozitifliklerinin Değerlendirilmesi. FLORA. 2015;20(3):12832.

16. Tümtürk A, Yeşil B. Hepatitis B, Hepatitis C and HIV seroprevalence among Syrian refugees: A crosssectional study from a tertiary referral center in Turkey. Hospital. 2018(58/29620911).

17. Syrian Arab Republic: WHO and UNICEF estimates of immunization coverage: 2017 revision. WHO 2018 [2021]. Available from: https://www.who.int/immunization/monitoring_ surveillance/data/syr.pdf.

18. UNICEF in Turkey worked closely with the Ministry of Health $(\mathrm{MoH})$ on vaccination campaigns for all refugee and migrant children under five in 2017. 2021 [cited 2021]. Available from: https://www.unicef.org/turkey/en/immunization.

19. Ergönül Ö, Tülek N, Kayı I, Irmak H, Erdem O, Dara M. Profiling infectious diseases in Turkey after the influx of 3.5 million Syrian refugees. Clinical Microbiology and Infection. 2020;26(3):307-12.

20. Ministry of interior Temporary Protection in Law on Foreigners and International Protection. 2021 2021 [cited 2021]. Available from: https://en.goc.gov.tr/temporary-protection-in-law-on-foreigners-andinternational protection.

21. Lavanchy D. The global burden of hepatitis C. Liver international. 2009;29:74-81. 
22. Chemaitelly H, Chaabna K, Abu-Raddad LJ. The epidemiology of hepatitis $\mathrm{C}$ virus in the Fertile Crescent: systematic review and meta-analysis. PloS one. 2015;10(8):e0135281.

23. Gökengin D, Doroudi F, Tohme J, Collins B, Madani N. HIV/AIDS: trends in the Middle East and North Africa region. International Journal of Infectious Diseases. 2016;44:66-73.

24. Inci A, Sarici IS, Caliskan G, Kalayci MU. Investigation of frequency of Hbsag, anti Hbs, anti Hcv and anti Hiv in refugee patients from syria who admit to a training and research hospital department of surgery. Acta Medica Mediterranea. 2017;33(1):59-63.

\section{Hosted file}

Table 1.docx available at https://authorea.com/users/418799/articles/525445-hbv-hcv-and-hivseroprevalence-in-syrian-refugee-patient-population-undergoing-preoperative-anaestheticassessment-a-10-year-survey-in-a-tertiary-teaching-hospital

\section{Hosted file}

Table 2.docx available at https://authorea.com/users/418799/articles/525445-hbv-hcv-and-hivseroprevalence-in-syrian-refugee-patient-population-undergoing-preoperative-anaestheticassessment-a-10-year-survey-in-a-tertiary-teaching-hospital

\section{Hosted file}

Table 3.docx available at https://authorea.com/users/418799/articles/525445-hbv-hcv-and-hivseroprevalence-in-syrian-refugee-patient-population-undergoing-preoperative-anaestheticassessment-a-10-year-survey-in-a-tertiary-teaching-hospital

\section{Hosted file}

Figure 1.docx available at https://authorea.com/users/418799/articles/525445-hbv-hcvand-hiv-seroprevalence-in-syrian-refugee-patient-population-undergoing-preoperativeanaesthetic-assessment-a-10-year-survey-in-a-tertiary-teaching-hospital 